Artículo Original

\title{
Bacterias patógenas en servicios higiénicos de una institución educativa superior
}

\section{PATHOGENIC BACTERIA IN HYGIENIC SERVICES OF A HIGHER EDUCATIONAL INSTITUTION}

\author{
GRACE THALÍA QUISPE BREÑA§*, SILVIA SALCEDO FERNÁNDEZ§
}

Recibido: 15 septiembre de 2018 / Aceptado: 07 noviembre de 2018

$\S E P$. Ingeniería Ambiental, Facultad de Ingeniería y Arquitectura, Universidad Peruana Unión, Perú.

\begin{abstract}
Resumen
Los fómites desempeñan un rol importante en la transmisión de microorganismos patógenos al ser superficies de uso cotidiano y especialmente si a estos objetos no se le proporciona normas adecuadas de aseo o si no existe una correcta higiene por parte de los usuarios. Por esta razón, el objetivo de este estudio fue determinar la presencia de bacterias patógenas del tipo coliformes fecales de la familia Enterobacteriaceae como Staphylococcus aureus, Klebsiella pneumoniae, Escherichia coli y Salmonella thypi en fómites empleados por multiusuarios, para lo cual, se realizó el estudio microbiológico de un total de 48 muestras recogidas de las perillas de las puertas y las palancas de los inodoros de los servicios higiénicos de varones y mujeres del primer piso de la Facultad de Ingeniería y Arquitectura de la Universidad Peruana Unión-Sede Lima. Las muestras fueron recogidas mediante la técnica del hisopado, para el posterior aislamiento en medio de cultivo selectivo, caracterización, identificación y las pruebas de Tinción Gram como prueba confirmativa de la identidad de bacterianas. Las cuatros especies bacterianas estuvieron presentes en los fómites analizados con ciertas diferencias en los días de muestreo, por lo que, al entrar en contacto con la piel pueden causar infecciones y ser nocivos para la salud del hombre.
\end{abstract}

Palabras clave: baño, coliformes fecales, fómites, contaminación

\begin{abstract}
The fomites play an important role in the transmission of pathogenic microorganisms to be surfaces of daily use and especially if these objects are not provided with adequate standards of cleanliness or if there is no proper hygiene by users. For this reason, the objective of this study was to determine the presence of pathogenic bacteria of the fecal coliform type of the family Enterobacteriaceae as Staphylococcus aureus, Klebsiella pneumoniae, Escherichia coli and Salmonella thypi in fomites used by multiusers, for which, the study was carried out microbiological of a total of 48 samples collected from the door knobs and the toilet levers of the male and female toilet services on the first floor of the Engineering and Architecture Faculty of the Universidad Peruana Unión-Sede Lima. Samples were collected using the swab technique, for subsequent isolation in selective culture medium, characterization, identification and Gram stain tests as confirmatory test of bacterial identity. The four bacterial species were present in the analyzed fomites with certain differences on the days of sampling, so when they come into contact with the skin they can cause infections and be harmful to human health.
\end{abstract}

Key words: bath, fecal coliforms, fomites, pollution 


\section{INTRODUCCIÓN}

A través de la historia y desde su existencia, los seres humanos han tenido que adaptarse a un ambiente dominado por una amplia diversidad de microorganismos que desempeñan roles importantes en los ecosistemas (Montaño, Sandoval, Camargo y Sánchez, 2010). La mayoría de ellos, son totalmente inofensivos e incluso algunos pueden ser beneficiosos para nuestra existencia (Neely y Sittig, 2002). Sin embargo, existen determinados ambientes o superficies inanimadas que pueden estar contaminadas por una variedad de microorganismos patógenos, los cuales suelen sobrevivir durante periodos prolongados (Del Águila y Laury, 2015).

Las bacterias son responsables de millones de muertes alrededor del mundo, pero también existen bacterias que no están ligadas a la frecuencia de muerte, pero que representan un problema de salud pública (Molina y Uribarren, 2017). La familia Enterobacteriaceae, se localizan como saprófitos en el tubo digestivo, pero también forman parte de la flora intestinal del hombre (simbiontes), y son los principales causantes de infecciones en el tracto respiratorio, digestivo, urinario, piel y tejidos blandos (Puerta y Mateos, 2010).

Los sanitarios son de uso esencial para cada ser humano, y el uso cotidiano incrementa los valores de presencia de patógenos. Por lo que la inadecuada limpieza de estos servicios podría facilitar la proliferación de bacterias patógenas, tan igual como podrían hacerlo otras superficies inanimadas como es el caso de las perillas de las puertas y las palancas del inodoro de los servicios higiénicos. Neely y Sittig (2002) indicaron que "Los microorganismos pueden entrar en contacto directo con las personas o ser transmitidos, por contacto indirecto, involucrando la participación de objetos inanimados, llamados fómites o seres vivos, llamados vectores".

Los servicios higiénicos de la Universidad Peruana Unión podrían conferir una posible fuente importante de alojamiento de diferentes tipos de microorganismos nocivos para la salud cuando las medidas de limpieza y desinfección no son las adecuadas en estas instalaciones y también cuando las normas de higiene por los usuarios no son las óptimas. Teniendo en cuenta los cientos de estudiantes, personal docente, administrativo y trabajadores del centro de aplicación de productos unión que comparten los sanitarios y el contacto físico directo en este espacio, resulta fácil comprender que pueden existir bacterias y gérmenes capaces de producir infecciones, lo que puede incrementar el riesgo de contraer enfermedades.

Detectar la presencia de bacterias potencialmente patógenas como Staphylococcus aureus, Klebsiella pneumoniae, Escherichia coli y Salmonella thypi en los fómites de los servicios higiénicos de Facultad de Ingeniería y Arquitectura (FIA) empleados por multiusuarios es un hecho trascendente, pues de este modo se lograría entender algunos aspectos de epidemiología que están relacionados en el proceso infeccioso por estos agentes microbianos, además de la importancia que cumplen estos objetos empleados diariamente como posibles fuentes de contaminación, y de este modo poner mayor atención a esta problemática y así aplicar medidas correctivas para disminuir el número de personas expuestas a adquirir contaminarse con estos organismos, ya sea mejorando los hábitos de higiene o aplicando desinfectantes sobre la superficie de las manijas y perillas (Del Águila y Laury, 2015). 
Este estudio tuvo el objetivo de determinar la presencia de Staphylococcus aureus, Klebsiella pneumoniae, Escherichia coli y Salmonella thypi en perillas de puertas y manijas de inodoro de los servicios higiénicos del primer piso de un pabellón de la Universidad Peruana Unión.

\section{MATERIALES Y MÉTODOS}

El estudio se realizó en el mes de septiembre de 2018. Dicho análisis consistió en el estudio de las bacterias presentes en las superficies lisas como las manijas de inodoros y perillas de puertas, utilizando la técnica del hisopado y su posterior aislamiento en agar MacConkey, así como la clasificación taxonómica de los aislamientos obtenidos (Betancur et al., 2010).

\section{ÁREA DE ESTUDIO}

El estudio se realizó en los servicios higiénicos de una institución educativa de nivel superior ubicada en el cono este de Lima (Perú) en el distrito de Lurigancho.

Las cepas se aislaron de las superficies lisas de las perillas de las puertas y palancas de los inodoros de los servicios higiénicos de varones y mujeres. Los ensayos microbiológicos se realizaron en el Laboratorio de Ciencias Biológicas de la Facultad de Ingeniería y Arquitectura.

En los diferentes ensayos que se realizaron en el presente estudio, se aplicaron las medidas de higiene para garantizar una buena calidad de la recolección de las muestras, empleando los equipos de protección personal. Además de tener en cuenta las medidas de bioseguridad a seguir en un laboratorio (Del Águila y Laury, 2015).

\section{PROCEDIMIENTOS}

\section{Preparación de materiales y medios de cultivo}

De acuerdo con Del Águila y Laury (2015), se fabricaron 16 hisopos que fueron esterilizados junto con los materiales de vidrio en la estufa a $168^{\circ} \mathrm{C}$ durante 2 horas para su posterior empleo.

Además, se necesitaron 20.62 g de Agar Mac Conkey para $400 \mathrm{ml}$ que fueron necesarios para 16 placas. Además de $4.5 \mathrm{~g}$ de Caldo TSB en $100 \mathrm{ml}$ para 18 tubos de ensayo.

Los medios de cultivo fueron preparados en matraces de $1000 \mathrm{ml} \mathrm{y} 250 \mathrm{ml}$ respectivamente. Posteriormente fueron esterilizados en la Autoclave a $121^{\circ} \mathrm{C}$ por 15 minutos y conservados.

\section{Tamaño de la muestra}

Para este estudio se realizaron tres muestreos programados cada martes durante tres semanas y en horario de la mañana, uno por semana para constatar la presencia de estos microorganismos. 
Se tomaron muestras representativas en tubos rotulados: 8 perillas de puertas y 8 palancas de inodoros de los servicios higiénicos de hombres y mujeres, esto con la técnica de hisopado.

Se empleó dos hisopos estériles por cada cubículo de baño que fueron previamente humedecidos en dos tubos con $10 \mathrm{ml}$ de Caldo Trypticasa de Soya.

Luego se procedió a frotar la superficie lisa de los fómites mencionados en sentido horizontal, vertical y diagonal.

Los hisopos utilizados fueron depositados en tubos de ensayo previamente pipeteados con $5 \mathrm{ml}$ de TSB.

\section{Transporte de las muestras}

Las muestras se transportaron en gradillas dentro de un cooler con hielera desde los baños de la Facultad de Ingeniería y Arquitectura hasta el Laboratorio de Ciencias Biológicas de la FIA, para incubarlas durante 24 horas a $37^{\circ} \mathrm{C}$, y posteriormente realizar el ensayo microbiológico.

\section{Análisis Microbiológico}

Los tubos que presentaron crecimiento (turbidez) en TSB, fueron resembrados en placas estériles con Agar Mac Conkey y se procedió a su incubación por 48 horas a $37^{\circ} \mathrm{C}$.

Posteriormente, a las colonias que presentaron crecimiento bacteriano, se le hizo la caracterización e identificación de las cepas bacterianas mediante Tinción Gram.

\section{RESULTADOS Y DISCUSIÓN}

Los datos se analizaron mediante estadística descriptiva, para establecer tablas de frecuencia absoluta, frecuencia relativa y frecuencia acumulada.

Para la determinación de las diversas bacterias halladas en los fómites de los servicios higiénicos de la Universidad Peruana Unión, se recolectaron un total de 48 muestras, obteniendo los resultados que se muestran en el Tabla 1.

De los 8 servicios higiénicos analizados, se obtuvieron 48 aislamientos en placas durante tres semanas de muestreo. De estos, el género más frecuente correspondió a Salmonella tiphy, presente en 20 placas $(41.6 \%)$; mientras que 9 placas $(18.8 \%)$ correspondieron a Escherichia coli; 8 placas (16.6\%) a Staphylococcus aureus y 4 placas $(8.3 \%)$ presentaron contaminación con Klebsiella (Tabla y Figura 1).

Las palancas de inodoro fueron contaminadas con 4 especies, entre ellas: 5 (20.8\%); 3 (12.5\%); $10(41.6 \%)$ y $3(12.5 \%)$ con Escherichia coli, Klebsiella, Salmonella tiphy, y Staphylococcus aureus respectivamente (Tabla 1).

De igual modo, las perillas de puerta también presentaron contaminación de 4 especies, entre ellas: 4 (16.6\%), 1 (4.16\%), 10 (41.83\%), y 5 (20.83\%) con Escherichia coli, Klebsiella, Salmonella tiphy, y Staphylococcus aureus respectivamente (Tabla 1). 
Tabla 1. Prevalencia de bacterias patógenas

\begin{tabular}{lcccccc}
\hline \multirow{2}{*}{ Fómites } & $\begin{array}{l}\mathrm{N}^{\circ} \text { de } \\
\text { placas }\end{array}$ & \multicolumn{3}{c}{ Prevalencia de las bacterias encontradas } & Total de placas \\
\cline { 3 - 6 } & & coli & Klebsiella & $\begin{array}{c}\text { Salmonella } \\
\text { tiphy }\end{array}$ & $\begin{array}{c}\text { Staphylococcus } \\
\text { contaminadas }\end{array}$ & \\
\cline { 3 - 6 } $\begin{array}{l}\text { Palancas de } \\
\text { inodoro }\end{array}$ & 24 & $5(20.8 \%)$ & $3(12.5 \%)$ & $10(41.6 \%)$ & $3(12.5 \%)$ & $21(87.4 \%)$ \\
$\begin{array}{l}\text { Perilla de } \\
\text { puerta }\end{array}$ & 24 & $4(16.6 \%)$ & $1(4.2 \%)$ & $10(41.6 \%)$ & $5(20.8 \%)$ & $20(83.2 \%)$ \\
\hline Total & $\mathbf{4 8}$ & $\mathbf{9 ( 1 8 . 8 \% )}$ & $\mathbf{4 ( 8 . 3 \% )}$ & $\mathbf{2 0}(\mathbf{4 1 . 6 \% )}$ & $\mathbf{8 ( 1 6 . 6 \% )}$ & $\mathbf{4 1 ( 8 5 . 3 \% )}$ \\
\hline
\end{tabular}

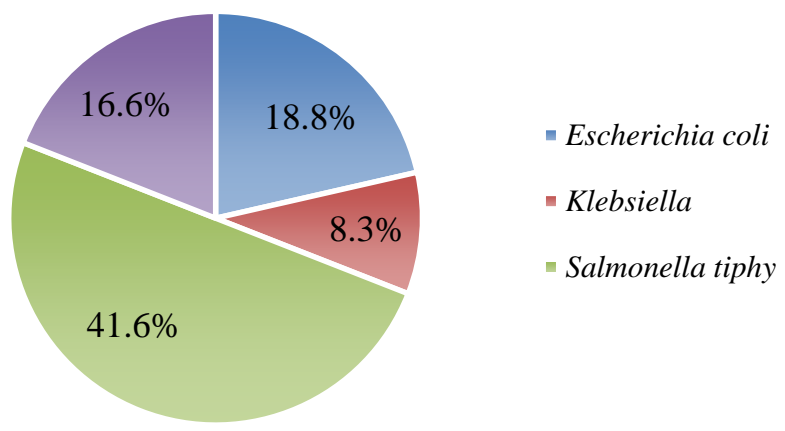

Figura 1. Prevalencia de bacterias halladas en las 48 muestras

De manera general se evidencia que las palancas de inodoro presentaron mayor contaminación que las perillas de puerta. La primera cuenta con 21 placas (87.4\%) contaminadas de las 48 placas en total, mientras que las perillas de puerta solo estuvieron contaminadas 20 placas $(83.2 \%$ ) (Tabla 1$)$.

Por consiguiente, los siguientes cuadros registran información dependiendo del tipo de usuario y según los fómites.

Se tomaron muestras de hisopado de las palancas de inodoro procedentes de 4 baños de mujeres y varones. Se obtuvieron 12 muestras durante las tres semanas de muestreo y en la cual se encontró mayor presencia de bacterias de Escherichia coli y Klebsiella en 3 placas $(25 \%)$ y 2 placas $(16.6 \%)$ respectivamente, en los baños de mujeres. Asimismo, la Salmonella tiphy se encontró por igual en ambos baños, en 5 placas $(41.7 \%)$. No hubo presencia de Staphylococcus aureus en el baño de mujeres pero si en el de varones en 3 placas $(25 \%)$. En consecuencia, los servicios higiénicos de varones presentaron mayor contaminación por diferencia de 1 placa, con respecto a la de las mujeres. Este cuenta con 11 placas contaminadas $(91.6 \%)$ de las 12 que se analizaron para los servicios higiénicos de varones (Tabla 2).

Tabla 2. Prevalencia de bacterias patógenas en palancas de inodoro, según el tipo de usuario

\begin{tabular}{lcccccc}
\hline \multirow{2}{*}{$\begin{array}{c}\text { Tipo de } \\
\text { Usuario }\end{array}$} & $\begin{array}{c}\mathrm{N}^{\circ} \\
\text { de placas } \\
\text { analizadas }\end{array}$ & $\begin{array}{c}\text { Escherichia } \\
\text { coli }\end{array}$ & Klebsiella & $\begin{array}{c}\text { Salmonella } \\
\text { tiphy }\end{array}$ & $\begin{array}{c}\text { Staphylococcus } \\
\text { aureus }\end{array}$ & $\begin{array}{c}\text { Total de placas } \\
\text { contaminadas }\end{array}$ \\
\hline $\begin{array}{l}\text { Baño de } \\
\text { Mujeres }\end{array}$ & 12 & $3(25 \%)$ & $2(16.6 \%)$ & $5(41.7 \%)$ & 0 & $10(83.3 \%)$ \\
$\begin{array}{l}\text { Baño de } \\
\text { Varones }\end{array}$ & 12 & $2(16.6 \%)$ & $1(8.3 \%)$ & $5(41.7 \%)$ & $3(25 \%)$ & $11(91.6 \%)$ \\
\hline
\end{tabular}


No se encontró presencia de Escherichia coli en los servicios higiénicos de mujeres, pero si en los de los varones en 4 placas (33.3\%), de igual forma la Klebsiella no estuvo presente en los servicios higiénicos de varones, al contrario, solo 1 placa $(8.3 \%)$ en el de las mujeres. Asimismo, la Salmonella tiphy se encontró por igual en ambos servicios higiénicos, en 5 placas (41.66\%). Mientras que el Staphylococcus aureus se halló en mayor cantidad en un $25 \%$ en el de mujeres y un $16.6 \%$ en el de varones (Tabla 3 ).

En consecuencia, los servicios higiénicos de varones presentaron mayor contaminación por diferencia de 4 placas, con respecto a las de mujeres. Este cuenta con 12 placas contaminadas (100\%) de las 12 que se analizaron. Y las otras con solo 8 placas $(66.6 \%)$ (Tabla 3).

Tabla 3. Prevalencia de bacterias patógenas en perillas de puerta, según el tipo de usuario

\begin{tabular}{|c|c|c|c|c|c|c|}
\hline \multirow{2}{*}{$\begin{array}{l}\text { Tipo de } \\
\text { Usuario }\end{array}$} & \multirow{2}{*}{$\begin{array}{c}\mathrm{N}^{\circ} \\
\text { de placas } \\
\text { analizadas }\end{array}$} & \multicolumn{4}{|c|}{ Prevalencia de especies encontradas } & \multirow{2}{*}{$\begin{array}{l}\text { Total de placas } \\
\text { contaminadas }\end{array}$} \\
\hline & & $\begin{array}{l}\text { Escherichia } \\
\text { coli }\end{array}$ & Klebsiella & $\begin{array}{c}\text { Salmonella } \\
\text { tiphy }\end{array}$ & $\begin{array}{c}\text { Staphylococcus } \\
\text { aureus }\end{array}$ & \\
\hline $\begin{array}{l}\text { Baño de } \\
\text { Mujeres }\end{array}$ & 12 & 0 & $1(8.3 \%)$ & $5(41.66 \%)$ & $2(16.6 \%)$ & $8(66.6 \%)$ \\
\hline $\begin{array}{l}\text { Baño de } \\
\text { Varones }\end{array}$ & 12 & $4(33.3 \%)$ & 0 & $5(41,66 \%)$ & $3(25 \%)$ & $12(100 \%)$ \\
\hline
\end{tabular}

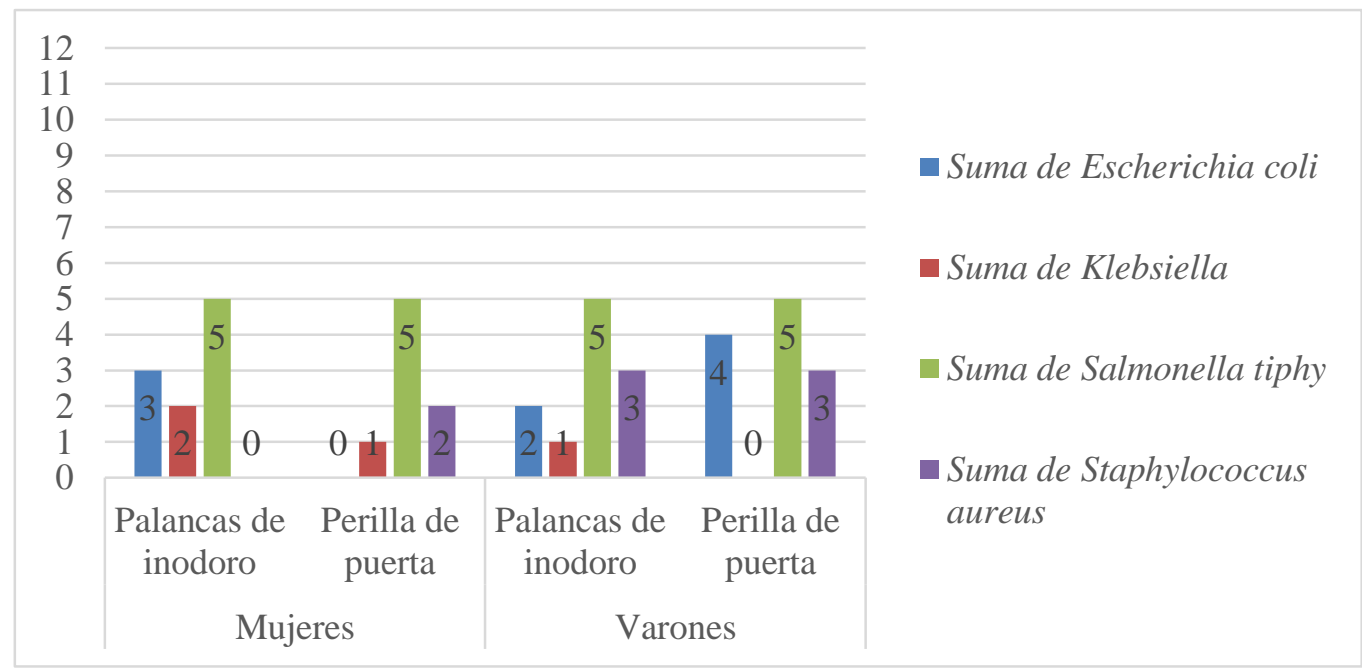

Figura 2. Prevalencia de bacterias patógenas, en palancas de inodoro y perillas de puerta de los baños de mujeres y varones. 
Resulta por lo tanto que los servicios higiénicos de varones presentaron mayor contaminación que el de las mujeres. Siendo 23 placas contaminadas $(47.9 \%)$ de las 48 muestras que se analizaron. Y solo 18 placas (37.5\%) en el caso de los servicios higiénicos de mujeres.

Tabla 4. Placas contaminadas según los fómites y el tipo de usuario en total

\begin{tabular}{lccc}
\hline Fómites & $\begin{array}{c}\mathrm{N}^{\circ} \text { de placas } \\
\text { en total }\end{array}$ & Baños de mujeres & Baño de varones \\
\hline $\begin{array}{l}\text { Palancas de } \\
\text { inodoro }\end{array}$ & 24 & $8(33.3 \%)$ & $12(50 \%)$ \\
Perillas de puerta & 24 & $10(41.6 \%)$ & $11(45.8 \%)$ \\
\hline Total de placas & $\mathbf{4 8}$ & $\mathbf{1 8 ( 3 7 . 5 \% )}$ & $\mathbf{2 3 ( 4 7 . 9 \% )}$ \\
\hline
\end{tabular}

Las diversas especies encontradas presentaron las siguientes características cuando se desarrollaron en el Agar MacConkey.

Tabla 5 . Características macroscópicas del desarrollo de las colonias en placas Petri

\begin{tabular}{ccccccccc}
\hline \multirow{2}{*}{ Especie } & \multicolumn{9}{c}{ Características de colonias en el Agar } & Coloración \\
\cline { 2 - 6 } del agar \\
\hline $\begin{array}{c}\text { Escherichia } \\
\text { coli }\end{array}$ & Mediano & $\begin{array}{c}\text { Púrpura y } \\
\text { rojizas }\end{array}$ & Circular & Plana & Enteros & Lisa & $\begin{array}{c}\text { Normal } \\
\text { Mantiene } \\
\text { coloración } \\
\text { original }\end{array}$ \\
\hline Klebsiella & Grande & $\begin{array}{c}\text { Rosadas } \\
\text { y morado } \\
\text { claro }\end{array}$ & Irregular & $\begin{array}{c}\text { Convexa } \\
\text { y elevada }\end{array}$ & Ondulados & Mucosas & Mucoide & $\begin{array}{c}\text { Mantiene } \\
\text { coloración } \\
\text { original }\end{array}$ \\
\hline $\begin{array}{c}\text { Salmonella } \\
\text { tiphy }\end{array}$ & Mediano & Negro & $\begin{array}{c}\text { Puntiforme } \\
\text { y circular }\end{array}$ & Plana & Enteros & Lisa & Normal & $\begin{array}{c}\text { Oscurece } \\
\text { el agar }\end{array}$ \\
\hline $\begin{array}{c}\text { Staphylococcus } \\
\text { aureus }\end{array}$ & Mediano & $\begin{array}{c}\text { Blanco y } \\
\text { beige }\end{array}$ & $\begin{array}{c}\text { Puntiforme } \\
\text { y circular }\end{array}$ & Plana & Enteros & Lisa & Normal & $\begin{array}{c}\text { Mantiene } \\
\text { coloración } \\
\text { original }\end{array}$ \\
\hline
\end{tabular}

En la identificación y caracterización macroscópica de las bacterias en las placas Petri se observó la presencia de colonias medianas, circulares de Escherichia coli de color rojo púrpura rodeadas de una zona de similar color; colonias grandes, irregulares de Klebsiella, caracterizadas por poseer colonias rosadas y con aspecto mucoide (Figura 3); colonias medianas, pequeñas, puntiformes de Salmonella tiphy de color negro y que oscurece el agar y finalmente; colonias con crecimiento puntiforme blancas/beige que corresponden al Staphylococcus aureus (Figura 4). 

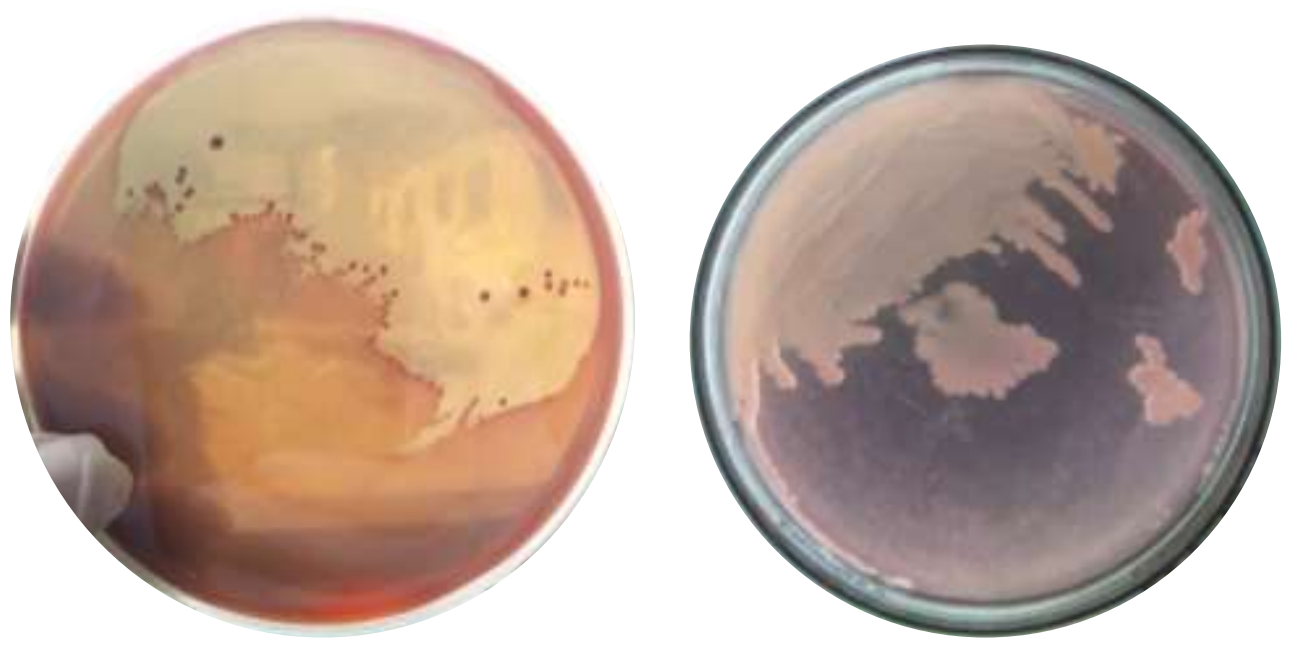

Figura 3. Colonias de Escherichia coli (izquierda) y de Klebsiella (derecha)
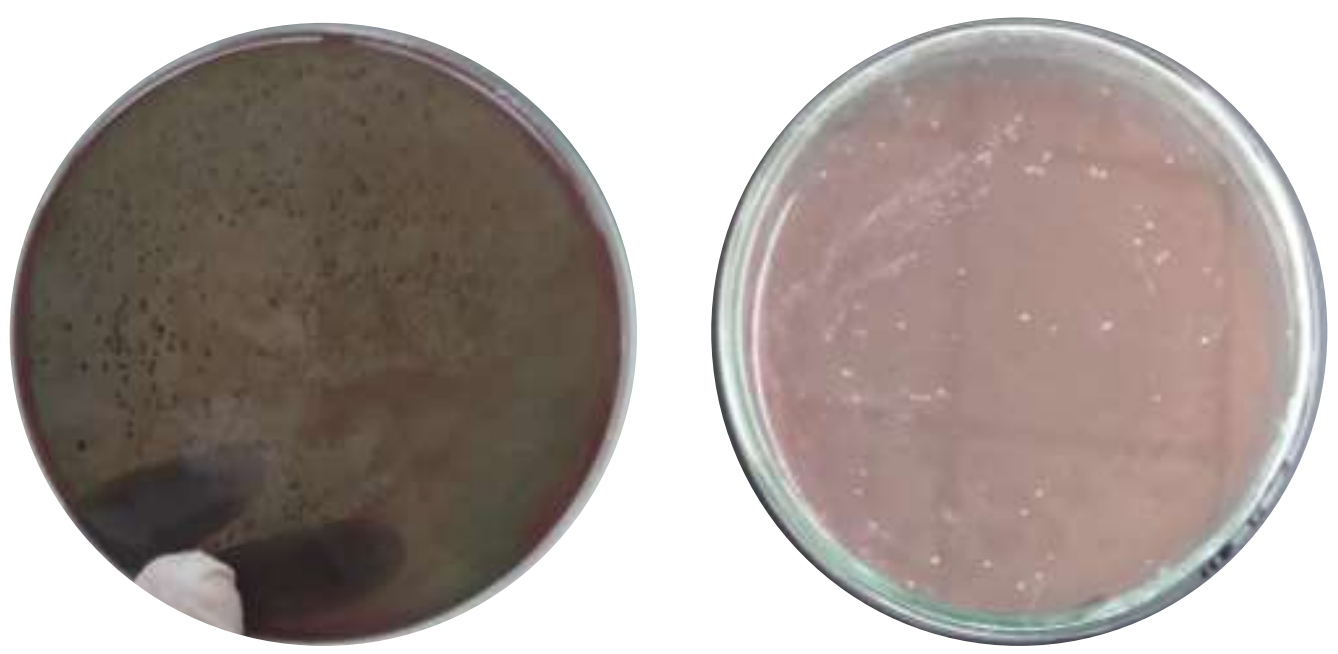

Figura 4. Colonias de Salmonella tiphy (izquierda) y Staphilococcus aureaus (derecha)

Posteriormente se realizaron las pruebas de Tinción Gram con la finalidad de confirmar la identidad de las bacterias encontradas. 
Tabla 6. Características microscópicas de las bacterias patógenas usando el microscopio

\begin{tabular}{c}
\hline Fotografía \\
\hline 5 \\
\hline 5
\end{tabular}

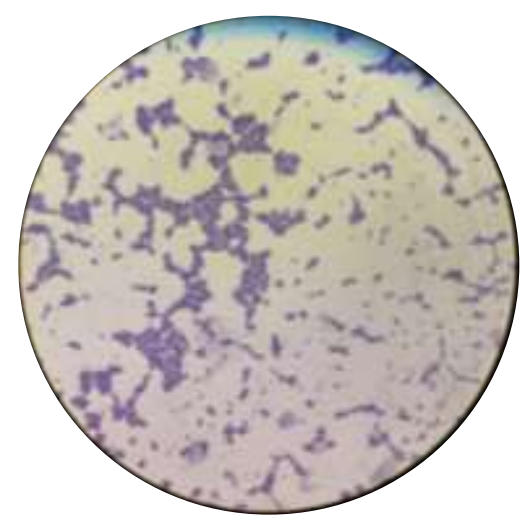

\section{Staphylococcus aureus}

Se observó a 40x 10x. Las bacterias gram positivas (color morado) en forma de racimos característicos de esta especie.

Los estudios desarrollados por Del Águila y Laury (2015), Flores et al. (2011), Gómez et al. (2011), Mandujano (2018) destacan la importancia de los fómites en los servicios higiénicos como principales fuentes de transmisión de enfermedades, sin embargo, se ha tomado muy poco interés en cuanto a la limpieza de estos y las consecuencias que podrían ocasionar.

En la Tabla 1 se aprecia que las palancas de inodoro presentaron mayor contaminación que la de las perillas de la puerta, por el hecho de que los usuarios jalamos directamente la palanca del inodoro después de realizar nuestras necesidades, contaminándolas directamente.

Moisse (2012) periodista de la ABC mundo hace énfasis en que las bacterias "quedan flotando por encima de 10 centímetros por encima del inodoro", esta idea es extraída de un estudio publicado a través de la revista de la Sociedad Estadounidense de Microbiológica, realizado en la Universidad de San Diego, en la cual analizaron la dispersión bacteriana luego de tirar de la palanca, la acción de jalar la cadena crea un remolino de bacterias que las eleva y se depositan en las superficies más cercanas, por tal hecho las palancas de inodoro presentan mayor contaminación. 
Según el estudio realizado por (Best, Sandoe y Wilcox, 2012) determinaron que las bacterias patógenas permanecen en los primeros minutos en mayor medida flotando en el inodoro alrededor de $21 \mathrm{~cm}$ a $10 \mathrm{~cm}$, después de tirar la cadena y que disminuyen en cantidad a medida que pase el tiempo siendo 2 o 3 horas, asimismo después de jalar la palanca algunas gotas salpican y contaminan el alrededor del inodoro del servicio higiénico. Asimismo, afirmaron que los inodoros convencionales sin tapa aumentan el riesgo de que la dispersión bacteriana sea más frecuente y en mayor cantidad.

En el caso de los retretes de los servicios higiénicos de varones y mujeres de la Facultad están confeccionados de tal manera que las palancas se hallan expuestas a esta dispersión bacteriana directamente y que sobretodo no poseen tapa de inodoro, siendo este de útil importancia puesto que minimiza la contaminación bacteriana. Otro estudio que corrobora esta información, es brindado por el investigador José Ramos Viva que dirige el laboratorio de Microbiología del IDIVAL, quien realizó un estudio para comprobar la eficiencia de tirar la cadena con la tapa baja del inodoro, ciertamente concluyó que, al realizar esta acción, no existiría dispersión y por consiguiente las superficies próximas no estarían contaminadas (Jiménez, P. 2018).

La especialista en Microbiología Clínica de la Universidad de Leicester (Reino Unido) Primrose Freestone, señala que "los mayores peligros que acechan los servicios higiénicos públicos se encuentran en la superficie y los objetos que puedan ser alcanzados por las salpicaduras generadas al jalar de la cadena del retrete, pues los microorganismos se disparan hacia el exterior, infectando así toda el área cercana al inodoro". Por ello, Freestone recomienda "abandonar el cubículo inmediatamente se jale de la cadena" (GM, 2018).

Por otra parte, el primer y último contacto que se tiene al ingresar a los servicios higiénicos son las perillas y manijas de las puertas (Huertas, 2017), siendo por ello que las perillas también presentan contaminación bacteriana y es un fómite ideal para ser transmisora de bacterias.

En lo que concierne a las especies que se hallaron en mayor cantidad el $43.75 \%$ de las 48 muestras fue la Salmonella typhi presentes de manera igual en las palancas de inodoro y perillas de puerta tanto para los servicios higiénicos de varones y mujeres. Sin embargo un estudio realizado por (Barker \& Bloomfield, 2000) en servicios higiénicos de familias de Reino Unido que habían padecido de Salmonelosis en el cual emplearon la misma técnica de hisopado; pero no aislaron las superficies de manijas de puerta, palancas de inodoro sino debajo del borde trasero de la taza del inodoro y el biofilm de este. Dictaminaron por lo tanto la presencia de Salmonella enteritidis y que sobrevivió después de 4 semanas acabada la enfermedad, en las superficies del baño pese a que se usaron productos de limpieza para descontaminar estas áreas. Lo que nos hace suponer que la Salmonella tiphy encontrada en los servicios higiénicos podrá persistir durante mucho tiempo y su definitiva eliminación será complicada.

Además, en los fómites analizados también se hallaron presencia de Escherichia coli y Klebsiella del género Enterobacter en cantidades considerables. Lo que reafirmaría el estudio realizado por Flores et al. (2011) en el cual reafirma que las bacterias halladas en las superficies de los baños, estaban relacionadas a los taxones de los intestinos, entre ellas las Enterobacter y que por lo general algunas especies residen en nuestro tracto intestinal y que no suponen ningún peligro.

José María Marimón, experto de la Sociedad Española de Enfermedades Infecciosas y Microbiología Clínica (SEIMC), indica que "Existen diferentes tipos de E. coli, la mayoría son inofensivos, pero en realidad representan una parte importante del contenido intestinal Revista de Investigación: Ciencia, Tecnología y Desarrollo (2018) 4(2):56 - 69 
de una persona humana. Sin embargo, algunos son capaces producir dolores relacionados con el tracto gastrointestinal" (Soteras, 2014).

Otro aspecto que se destaca es la importancia de la microbiota intestinal, en especial del tracto intestinal, que, "en condiciones fisiológicas, impide la colonización de la piel por otras especies bacteriana a través de un mecanismo de interferencia bacteriana, el cual evita de manera eficiente el establecimiento de microorganimos oportunistas y/o patógenos" (Ulloa, Castillo, Solís, Arévalo y Rojas, 2011)

Sin embargo, cabe destacar que el Staphylococcus aureus solo se halló en un 8.3\% del 48 de muestras analizadas, siendo la bacteria hallada en menor cantidad en comparación que las otras. Pero en el estudio realizado por (Gibbons et al., 2015) en el que analizaron del mismo modo las superficies de los baños, luego de que los usuarios abandonaron el ambiente en distintas horas, determinaron que el género más aislado fue el Staphylococcus incluso después de varias horas de la exclusión humana. Aunque también se hallaron aquellas bacterias relacionadas a los taxones intestinales.

Las enfermedades provocadas por estas especies del género Enterobacter, que se caracterizan por ser gram negativos y por su localización habitual como saprófitos en el tubo digestivo (Puerta y Rodríguez, 2010) y que tienen como característica común en producir síntomas de dolores estomacales, diarreas, fiebres, etc. en quienes se contagian de estas bacterias por las malas prácticas de higiene, etc. Además, los aumentos de estas enfermedades se han reportado en los hospitales de salud pública. Entre tanto "El impacto de las cepas de $S$. aureus sobre la salud es la resistencia que puede presentar a múltiples antibióticos, sobre todo a la meticilina" (Cervantes y García, 2014). Y que sobretodo "Es importante tener en cuenta que la Salmonella es altamente contagiosa, por lo que todas las medidas de higiene ayudarán de forma directa a evitar el contagio" (Barisione et al. 2014).

Por esta razón, el control general de infecciones por cualquier cepa de E. coli, Salmonella y Klebsiella exige mejores condiciones sanitarias, ambientales, e higiene personal (Molina y Eslava, 2015).

En general, "educar a las personas en el lavado de manos, el uso de papel y el conocimiento de los sistemas y métodos de limpieza y desinfección de las instalaciones de baños públicos, así como el uso adecuado de los productos para cada tipo de superficie, resulta ser vital para la prevención de enfermedades de origen fecal" ("Los baños públicos y el temor al contagio de enfermedades", 2015).

\section{CONCLUSIONES}

Staphylococcus aureus, Klebsiella pneumoniae, Escherichia coli y Salmonella thypi están presentes en las palancas de los inodoros y las perillas de las puertas de los servicios higiénicos de la institución de educación superior en la ciudad de Lima.

Los fómites que presentaron mayor contaminación fue el de las palancas de inodoro que cuenta con 21 placas $(87.5 \%$ ) contaminadas de las 48 placas en total, mientras que las perillas de puerta solo estuvieron contaminadas 20 placas (83.3\%). Por el hecho de que al jalar la cadena se liberan muchas bacterias en forma de remolino alcanzando hasta los $21 \mathrm{~cm}$ suspendidas en el aire por encima del inodoro, contaminando las superficies cercanas.

Existen diferencias entre los resultados del último muestreo antes de la limpieza, pues presentaron contaminación de Salmonella thypi en comparación con los primeros resultados 
cuando se había realizado la desinfección respectiva en donde esta bacteria estaba ausente, pero existía un grado de contaminación por Staphylococcus aureus, Klebsiella pneumoniae y Escherichia coli.

La deficiente limpieza de los servicios higiénicos podría ser una de las razones por las que existe una contaminación de los fómites estudiados teniendo en cuenta la cantidad de multiusuarios que hacen uso de estos baños.

En base a las cepas patógenas encontradas dentro de la institución, se deben aplicar medidas correctivas como el uso de otros desinfectantes, la frecuencia de la limpieza y la higiene de cada usuario.

Es de conocimiento la importancia de la limpieza y el orden en toda organización, es así como en el artículo 37 de la Resolución Ministerial N³75-2008-TR indica que los servicios higiénicos deben estar limpios en todo momento, por lo que es requisito para evitar sanciones de las faltas del mismo.

\section{RECOMENDACIONES}

Se recomienda abandonar el cubículo inmediatamente después de jalar la palanca del inodoro, además de practicar correctas normas de higiene personal como lavarse las manos con agua y jabón o algún desinfectante a base de alcohol y el uso de papel después de hacer uso de los servicios higiénicos.

Del mismo modo, el conocimiento de los sistemas y métodos de limpieza y desinfección de las instalaciones de baños públicos, así como el uso adecuado de los productos para cada tipo de superficie, resulta ser vital para la prevención de enfermedades de origen fecal.

\section{Agradecimientos}

Al Laboratorio de Ciencias Biológicas de la Universidad Peruana Unión por otorgar facilidades logísticas para el desarrollo de esta investigación.

\section{Referencias}

Barisione, G., Gallero, S., Hogde, D. y Maldonado, N. (18 de setiembre de 2014). Prevención. Recuperado de: http://salmonella2014.blogspot.com/2014/09/ prevencion.html

Barker, J., \& Bloomfield, S. F. (2000). Survival of Salmonella in bathrooms and toilets in domestic homes following salmonellosis. Journal of Applied Microbiology, 89(1), 137-144. https://doi.org/10.1046/j.1365-2672.2000.01091.x

Best, E. L., Sandoe, J. A. T., \& Wilcox, M. H. (2012). Potential for aerosolization of Clostridium difficile after flushing toilets: the role of toilet lids in reducing environmental contamination risk. The Journal of Hospital Infection, 80(1), 1-5. https://doi.org/10.1016/j.jhin.2011.08.010

Betancur, C., Estrada, S., Ceballos, M., Sánchez, E., Abad, M., Vanegas, C. y Salazar, L. (2010). Billetes como fómites de bacterias con potencial patógeno para el hombre. Infectio, 14(2), 120-126.

Cancino Bautista, L. P., Martinez De Los Santos, L. P., \& Gutierrez Rincon, A. N. (2013). 
El uso y la higiene de los sanitarios del cobach 145 . Chiapas, Mexico.

Cervantes, E., García, R., y Salazar, P. (2014). Características generales del Staphylococcus aureus. Revista Latinoamericana de Patología Clínica y Medicina de Laboratorio, 61(1), 28-40.

Del Águila, P. y Laury, K. (2015). Presencia de Escherichia coli y pseudomonas aeruginosa en fómites empleados por multiusuarios en la ciudad de Iquitos (tesis de pregrado). Universidad Nacional de la Amazonía Peruana, Iquitos, Perú.

Flores G., Bates, S., Knights, D., Lauber, C., Stombaugh, J., Knight, R., y Fierer, N. (2011). Microbial Biogeography of Public Restroom Surfaces. Plos ONE, 6.

Gibbons, S. M., Schwartz, T., Fouquier, J., Mitchell, M., Sangwan, N., Gilbert, J. A., \& Kelley, S. T. (2015). Ecological succession and viability of human-associated microbiota on restroom surfaces. Applied and Environmental Microbiology, 81(2), 765-73. https://doi.org/10.1128/AEM.03117-14

GM. (26 de junio de 2018). ¿A qué peligros nos exponemos en los baños públicos? Recuperado de https://www.grandesmedios.com/peligros-banos-publicos/

Gómez, D., Lavayén, S., Nario, F., Piquin, A., y Zota, M. (2011). Detección de microorganismos potencialmente patógenos en hogares de Mar del Plata. Acta Bioquímica Clínica Latinoamericana, 45(3), 441-5.

González Y.M.G, Rodríguez, C., Zúñiga , G., Favela , H., \& García , L. (14 de abril de 2015). Microorganismos de interés clínico aislados de teléfonos móviles. QuímicaViva.

Huertas, E. (29 de abril de 2017) Esto es lo que hacemos mal en un baño público. RPP Noticias. Recuperado de https://vital.rpp.pe/vivir-bien/esto-es-lo-que-hacemos-malen-un-bano-publico-noticia-1047249

Jiménez, P. (1 de marzo de 2018). Esta es la razón por la que deberías cerrar la tapa del váter antes de tirar de la cadena. Vozpópuli. Recuperado de https://www.vozpopuli.com/memesis/bacterias-vaterexperimento_0_1113489226.html.

Ministerio de Trabajo y Promoción del Empleo (2008). Resolución ministerial №375-2008TR por la cual Aprueban la Norma Básica de Ergonomía y de Procedimiento de Evaluación de Riesgo Económico. Lima. Ministerio de Trabajo y Promoción del Empleo.

Moisse, K. (2 de enero de 2012). Flushing Can Spread Diarrhea Disease. ABCNews. Recuperado de https://abcnews.go.com/blogs/health/2012/01/02/flushing-canspread-diarrhea-disease/

Molina López, J., \& Uribarren Berrueta, T. (30 de Noviembre de 2017). Universidad Nacional Autónoma de México.

Molina, J. y Eslava, C. (3 de agosto de 2015). Escherichia coli diarrogénica. Recuperado de http://www.facmed.unam.mx/deptos/microbiologia/bacteriologia/escherichiacoli.html

Molina, J. y Uribarren. T. (30 de noviembre de 2017). Generalidades de bacterias. Recuperado http://www.facmed.unam.mx/deptos/microbiologia/bacteriologia/generalidades.html

Montaño Arias, N. M., Sandoval Pérez, A. L., Camargo Ricalde, S. L., \& Sánchez Yáñez, J. M. (2010). Los microorganismos: pequeños gigantes. Ciencia y cultura Elementos, 1523.

Montaño, N., Sandoval, A., Camargo, S., y Sánchez, J. (2010). Los microorganismos: pequeños gigantes. Ciencia y cultura Elementos, 77, 15-23.

N.D. (2 de octubre de 2015). Los baños públicos y el temor al contagio de otras enfermedades. Última Hora. Recuperado de https://www.ultimahora.com/los-banospublicos-y-el-temor-al-contagio-enfermedades-n935504.html 
Neely, A., y Sittig, D. (2002). Basic microbiologic and infection control information to reduce the potential transmission of pathogens to patients via computer hardware. Journal of the American Medical Informatics Association, 9(5), 500-508.

Neely.A, \& Sittig.D. (2002). Basic microbiologic and infection control information. J Am Med Inform Assoc, 500-508.

Papel Matic. (2016). El contagio de infecciones en baños públicos.

Prisscilla, D. Á., \& Laury Silva, K. (2015). Presencia de Escherichia coli y Pseudomonas aeruginosa en fomites empleados por multiusuarios en la ciudad de Iquitos. Iquitos, Perú.

Puerta, G. A., \& Mateos, R. F. (2010). Enterobacterias. Albacere.

Puerta, M., y Mateos, F. (2010). Enterobacterias. Medicine, 10(51) 3426-31.

Rodríguez, J., Zúñiga, G., Gonzáles, M., Favela, J., y García, L. (2015). Microorganismos de interés público aislados de teléfonos móviles. Química Viva, (1), 103-110.

Soteras, A. (14 de enero de 2014). EFESalud. España. Recuperado de https://www.ultimahora.com/los-banos-publicos-y-el-temor-al-contagioenfermedades-n935504.html

Trujillo, Y. (2018). Grado de contaminación microbiana de los cepillos dentales guardados en el baño y dormitorio de los estudiantes de Odontología de la Universidad de Huánuco 2017 (tesis de pregrado). Universidad de Huánuco, Huánuco.

Ulloa, M., Castillo, L., Solís, F., Arévalo, G., y Rojas, J. (2011). Colonización bacteriana de piel sana versus quemada de niños bajo 15 años en COANIQUEM, Santiago de Chile. Chil Infect, 29(1), 49-54. 